\title{
Manipulation of Safety Training Practices on Organizational Safety Performance: An Evidence in Malaysia's Automotive Industry
}

\author{
Shah Rollah Abdul Wahab, Azizah Rajab, Roziana Shaari, Siti Aisyah Abdul Rahman, and Maisarah \\ Mohamed Saat
}

\begin{abstract}
This paper aims to investigate the role of safety training practices to safety performance in Malaysia's automotive industry. This study adopts a non-experimental type research which employs questionnaire as the method of collecting data. The measurement tool undertaken in the data collection is Safety Performance Scale that developed by Wu et al. (2007). A total of 696 employees from Malaysia automotive manufacturing and assembly plants are selected as the respondents of this study. The selection of respondents is made using systematic sampling design. Data of the study are then analyzed using canonical correlation analysis. The finding of the study highlights that safety training practices plays a significant influence to an organization's safety performance $\left(r^{2}=0.631, p<0.001\right)$.
\end{abstract}

Index Terms-Safety at work, safety training practices, safety performance, and malaysia's automotive manufacturing and assembly plants.

\section{INTRODUCTION}

Considerable attention is given to safety assessment by industries in view of the hazards that are present in the workplace [1]. International Labor Organization (ILO) had reported that each minute twenty-one employees are involved in workplace accidents and as the consequence over 270 million of those involved will be absent from work for at least the next three days [2]. Based on that one could claim that workplace accidents are economically and legally costly and as the result it has received and should be given critical attention [3]. Many view workplace safety of an organization in association with the frequency of injuries and accidents that happen there. Total number in the earlier ILO report which is frightening and widespread shows that the role of safety in an organization should be given major attention. Proven and documented is the fact that almost 350000 employees are injured each day and almost 1000 of them lost their lives to workplace accidents [2].

Industrial revolution which occured at the end of eighteen

Manuscript received July 17, 2013; revised September 20, 2013.

Shah Rollah Abdul Wahab, Roziana Shaari, Siti Aisyah Abdul Rahman, and Maisarah Mohamed Saat are with the Faculty of Management, Universiti Teknologi Malaysia, 81310 UTM Skudai Johor, Malaysia (e-mail: shah@ management.utm.my, rozianas@ management.utm.my, siti aisyah@ management.utm.my, maisarah@ management.utm.my).

Azizah Rajab is with the Language Academy, Universiti Teknologi Malaysia, 81310 UTM Skudai Johor, Malaysia (e-mail: azizahrajabutm@yahoo.com). centuries gave birth to safety controversy [4]. High demand of goods and the entreprenuers' greed were revealed in considerable amount of literature as the two main reasons that lead to workplace accidents during that era. Employees worked in unsafe environment and at the same time they also faced overworking issues [5]. The livelihood and wealth of a country in many ways are dependable on industries, thus to develop its economy good turn out from industries is very important. It is reported in the most recent literature that simultaneously about 35000 multinational companies are reported to be operating worldwide contributing to almost o seventy per cent of the world trading activities [6]. Malaysia statistic shows that manufacturing industry has also become an important sector and plays and important role towards the country development. In 2007, for example industrial sector contributes to more than a quarter of Gross Domestic Product, which is (30.1\%), 2008 (29.8\%), 2009 (29.5\%) and $2010(26.2 \%)$ [7]. SOCSO's statistic however shows that there is staggering number of workplace accidents in line with the rapid development of manufacturing industry.

As the result of on-going discussions on the source of workplace accidents, it is salient that that safety performance has a strong effect on employees' KSA [8]. However researches have shown that the most significant approach to improve employees' safety awareness and safety behaviours is through safety training practices [9]-[11] but scholars [12]-[13] claimed that many organizations do not give proper attention and effort for safety training. It is due to the management's failure in appreciating the importance of safety training because they believe that the training has little effect in upgrading safety performance besides taking the employees' time off their work [14]. The matter became worse as some leaders not only refuse to support safety training, they also deny the fact that it is a very effective way of involving employees in workplace safety [15].

As the summary for this section, it is clear that safety management is practiced in today's organizations, however, management's denial to consider the importance of training practices may limit its efficiency in managing safety performance. The serious number of workplace accidents highlights the fact that there is the volatility in heavy industry safety level. Thus this inconclusive finding on safety training practices to safety performance has motivated the researcher to investigate the phenomena of safety issue in Malaysia setting. 


\section{LinKAGE OF SAFETY TRAINING PRACTICES AND SAFETY PERFORMANCE}

Safety training occurs when there is a steady process of encouraging safety awareness and safety KSA on the part of the employees which is achieve when there are changes at work in safety procedures and its relevant regulations [16]. It is believed that training activity is the key in assisting employees to become familiar with the existing safety procedures and policies at the working environment [14]. One could say that there is success in safety training when the employees not only follow the safety rules and regulation but also practice them in their work to ensure their safety [17], [18]-[19]. Lately, trained employees in organization is looked upon as competitive advantage, thus all employees regardless of the level of their work risk will be given safety training [20]. Health and Safety at Workplace (1974) for the UK, Occupational Safety and Health Act (1970) in the US and even Occupational Safety and Health Act (1994) in Malaysia have also stressed on the importance of providing safety training to employees and at the same time draw safety legislations for the employees benefit.

Currently there is diversity of organizations workforce and to meet the challenges of such diversity one could see that safety training is evolving rapidly [21] as it is common that the management will take the effort of making everyone in the organization involve in one [16]. The same fact had been stressed by [22] who claimed that it is not easy to ignore that providing training to employees is crucial as it contributes success of safety efforts at work. Therefore, both management and employees have their own part to play in maintaining a safer workplace. In this case the key personnel turn out to be individuals in organizations that hold the important responsibility of providing more comprehensive safety training besides ensuring that employees are prepared to practice training content [23]. Employees that are involved should be given the credit because they have shown and created greater safety awareness which has a significant result on the organizations cost saving [24]. To ensure that happens, the management must consider the employees' ability to attain organizational goal including safety training and it is also necessary for management to identify the performance gap among employees before planning safety training in the organizations.

According to Colling [5] safety training is a catalyst in improving organizational safety performance besides nurturing more supportive working environment. To promote a safer workplace, all employees must be aware of their safety roles and they must commit themself in practicing their role. The employees must arrive to the fact that safety training is generally understood as one of the means of improving productivity and reducing the compensation claims and lost time due to injuries and accidents. Among the practices that enhance an employee ability to practice safety behaviors include putting on personal protection equipment (PPE) when performing their jobs at the workplace [25]. It is assumed that having little knowledge is dangerous and a complete lack of knowledge is certainly worse [26] therefore the management should not expect sudden changes in employees' performance and must give some time before behavioural changes really take place because [27] had proven that changes will been seen six months after the safety training in the form of constructive feedback.

Becker and Morawetz's [28] longitudinal study on 55 workers in The International Chemical Workers Union Council in Ohio and [29] study among 5542 local South Australian students are among the significant number of the researches on safety training which show that raising safety awareness through safety training among employees has become the crucial factor to improve safety performance. The first proved that safety training has bring substantial improvement to employees such as raising employees' awareness on safety and self-efficacy to become better while the latter ascertained that the training has improved self-confidence and safety skills among employees before performing jobs at the workplace. Stormgren and Andersson [30] had made an investigation on 72 Swedish municipalities and they confirmed that safety training has become the key factor to encourage an effective usage of safety management tools at work. Those are only three among many significant researches which not only highlight the importance of safety training which includes the fact that it should be made universal in an organization's community regardless of employment levels and indicate that safety training has a great influence to organizational performance.

However, [23] claimed that some employees reported they were not given even the basic training because their management viewed safety at workplace as unimportant. As highlighted in [31], the assessment is less commonly measured and the evidence is often anecdotal and doubtful methodology. This shows that in spite of all the researches, there exist a certain strong number of organizations that still view training effort as not important in their plan.

\section{RESEARCH METHOD}

To respond to the objectives of the study which is related to safety training in correlational with its research design the researcher has taken 696 production employees from Malaysia's automotive manufacturing and assembly plants as respondents. The questionnaire from [32] Safety Performance Scale with the value of Alpha Cronbach 0.987 is used as an instrument to collect data for the study. Respondents answer the questionnaire using a five Likert scale ranging from "extremely disagree" to "extremely agree". The data were analyzed by using simple linear regression analysis to identify the effect of safety training practices on safety performance.

\section{FINDINGS AND DisCUSSION}

As explained in the review of literature, far too little attention has been made to explain the role of safety training practices on safety performance in Malaysia's automotive industry. However, the literature assumes that safety training practices plays an important role to attain the organizational safety goals. In this paper, simple linear regression analysis is carried out to investigate an ability of safety training practices in predicting safety performance. The tested null hypothesis and equation of the regression are shown as 
follows.

$H_{0}$ : Safety training practices do not affect safety performance

Equation: Safety performance $=i+b_{1}$ safety training practices

$+e$

where: $b_{1}=$ coefficient for safety training practices

$i=$ constant value for safety performance

$e=$ regression residual

TABLE I: THE EFFECT OF SAFETY TRAINING PRACTICES ON SAFETY PERFORMANCE

\begin{tabular}{cccc}
\multicolumn{4}{c}{ PERFORMANCE } \\
\hline Variable & $\mathrm{R}^{2}$ & $\mathrm{~F}$ & Sig \\
\hline $\begin{array}{c}\text { Safety Training Practices on Safety } \\
\text { Performance }\end{array}$ & $.631^{* * *}$ & 459.374 & .000
\end{tabular}

Note: $* * * p$ value $<0.001$

Table I indicates the findings on regression analysis concerning the prediction of safety training practices to influence safety performance. R squared 0.631 highlights that safety training practices contributes 63.1 percent of variance in safety performance $(F(1,693)=459.374, p<$ $0.001)$. The observed significant value 0.000 is less than the significant level (0.001) and thus cannot accept the tested null. It implies that manipulation of safety training practices has able to improve organization's safety performance.

Various possibilities arose from the results, but first and foremost it is clear that safety training turned out to be the most approachable method to propagate safety information to employees. The training provides great chances for the organizations to communicate their safety expectation especially to new employees. The management has taken serious attention in employees well-being by improving individual and organizational safety performance through careful selection of trainers and the method in which safety training are carried out. The organizations believe that one of the most important aspects that will help them achieve safety training objectives which will work simultaneously in improving safety performance is to engage experienced and knowledgeable safety trainers. This support the result of [3] that highlights serious attention on safety training process is vital in attaining safety objectives that are developed at working environment. On the other hand training provides the opportunity for employees to openly and critically discuss arising safety issues in the working environment.

Safety training assists employees to effectively manage PPE at their working stations is an undeniable factor which is one of the basic approaches used by the management in aiding and improving organizational safety performance. Besides, safety training also allowed employees to feel that they are working in a safe environment which happened because of the realization that they have the knowledge on safety procedures which they acquired during the training session. One could not deny the fact that severity of workplace accidents depends on how the employees handle intolerable incidents. For that reason, safety training is as an important technique to reduce employees' uncertainties on how to react when they encountered unsafe situations at their workplace. The finding is consistent to the research output by
[17] who concludes that safety training increases employees' safety awareness and knowledge in handling emergency situation in organizations. However this effort will go to waste when employees fail to manage PPE appropriately. Current studies show that most of production employees have been provided and received comprehensive safety training for first aider by the management which is a fact that shows organization's attitude concerning their workers safety when emergencies occur while working. The aiders help to reduce the stage of victims' severity and also control the chaotic situation due to the accidents which reflects the success of the comprehensive training which has enabled the aiders to give appropriate and immediate response to workplace accidents victims.

To conclude the researcher has shown that safety performance is not solely the question of technical solution; it has a lot to do with people-related issues thus safety training practices must be tailored for overall employees' interest and organizational goal for the sake of promoting a safer workplace. Its achieved when employees are not only skillful in their work but also skillful in their safety training practices.

\section{ACKNOWLEDGMENT}

The work was sponsored by Ministry of Higher Education Malaysia and Universiti Teknologi Malaysia.

\section{REFERENCES}

[1] R. Flin, K. Mearns, P. O'Connor, and R. Bryden, "Measuring Safety Climate: Identifying the Common Features," Safety Science, vol. 34, pp. 177-192, 2000

[2] P. Hamalainen, "The effect of globalization on occupational accidents," Safety Science, 2008.

[3] K. J. Mearns and S. Yule, "The role of national culture in determining safety performance: Challenges for the global oil and gas industry," Safety Science, 2008.

[4] N. Budworth, "The importance of health and safety in the modern world," in Proc. Speech Note of the APOSHO 22nd Conference. Bangkok, Thailand, 2006.

[5] D. A. Colling, Industrial Safety: Management and Technology, New Jersey: Prentice Hall, 1990.

[6] J. LaDou, "International occupational health," International Journal of Hygiene and Environmental Health, vol. 206, no. 4-5, pp. 303-313, 2003.

[7] Ministry of Finance Malaysia. (2010). Economy report 2009/2010: economy performance and prospect. [Online]. Available: http://www.treasury.gov.my/pdf /ekonomi/le /0910/jp2_3.pdf

[8] B. Shulruf, and A. Balemi, "Risk and preventive factors for fatalities in all terrain vehicle accidents in New Zealand," Accident Analysis and Prevention, vol. 42, pp. 612-618, 2010.

[9] W. L. Eddie, H. Cheng, D. P. Li, F. Fang, and J. Xie, "Construction safety management: an exploratory study from china," Journal of Construction Innovation, vol. 4, pp. 229-241, 2004.

[10] T. M. Lippin, A. Eckmen, K. R. Calkin, and T. H. McQuiston, "Empowerment-based health and safety training: evidence of workplace change from four industrial sector," American Journal of Industrial Medicine, vol. 38, pp. 697-706, 2000.

[11] R. C. Jensen, "Safety training: flowchart model facilitates development of effective course," Journal of Professional Safety, vol. 50. no. 2, pp. 26-32, 2005.

[12] P. Hamalainen, "The effect of globalization on occupational accidents," Safety Science, 2008.

[13] J. Harvey, H. Bolam, D. Gregory, and G. Erdos, "The effectiveness of training to change safety culture and attitudes within a highly regulated environment," Personnel Review, vol. 30, no. 6, pp. 615-636, 2001.

[14] W. K. W. Ismail and N. S. N. F. Yani, "Latihan dan Prestasi Kerja dalam Menggunakan Automasi Industri," Jurnal Kemanusiaan, vol. 5, pp. 1-10, 2005.

[15] J. L. Bell, and S. T.Grushecky, "Evaluating the effectiveness of a logger safety training program," Journal of Safety Research, vol. 37, pp. 53-61, 2006. 
[16] S. C.-K. Yu and B. Hunt, "A fresh approach to safety management system in Hong Kong," The TQM Magazine, vol. 16, no. 3, pp. 210-215, 2004.

[17] J. M. Ekenes, "Effective safety training programs for aluminium cast shops," JOM, vol. 53, no. 11, pp. 14-15, 2001.

[18] T. O'Connor, D. Loomis, C. Runyan, J. A. de Santo, and M. Schulman, "Adequacy of Health and Safety Training Among Young Latino Construction Workers," Journal of Occupational and Environmental Medicine, vol. 47, no. 3, pp. 272-277, 2005.

[19] B. L. Weidner, A. R. Gotsch, C. D. Delnevo, J. B. Newman, and B. McDonald, "Worker health and safety training: assessing impact among responders," American Journal of Industrial Medicine, vol. 32, pp. 241-246, 1998.

[20] D. D. Galbraith and S. E. Fouch, "Principles of Adult Learning: Application to Safety Training," Professional Safety, vol. 52, no. 9, pp. 35, 2007.

[21] S. Mukherjee, L. Overman, L. Leviton, and B. Hilyer, "Evaluation of worker safety and health training," American Journal of Industrial Medicine, vol. 38, pp. 155-163, 2000.

[22] R. B. Dodge, "Unintentional learning and the occupational health and safety experience," Education and Training, vol. 40, no. 3, pp. 109-114, 1998.

[23] C. S. Mitchell, M. L. Doyle, J. B. Moran, B. Lippy, J. T. Hughes, M. Lum, and J. Agnes, "Worker Training for New Threats: A Proposed Framework," American Journal of Industrial Medicine, vol. 46, pp. 423-431, 2004.

[24] J. B. Henning, C. J. Stufft, S. C. Payne, M. E. Bergman, M. S. Mannan, and N. Keren, "The influence of individual differences on organizational safety attitudes," Safety Science, 2008.

[25] X. Dong, P. Entzel, Y. Men, R. Chowdhury, and S. Schneider, "Effects of safety and health training on work related injury among construction laborer," Journal of Occupational and Environmental Medicine, vol. 46, no. 12, pp. 1222-1228, 2004.

[26] B. L. Weidner, "Testing as a measure of worker health and safety training: perspectives from a hazardous materials program," American Journal of Industrial Medicine, vol. 37, pp. 221-228, 2000.

[27] A. M. Al-Hamed and M. M. Al-Asfoor, "A behavior based safety approach at a kuwait research institution," Journal of Safety Research. vol. 37, pp. 201-206, 2006

[28] P. Becker and J. Morawetz, "Impacts of health and safety education: comparison of worker activities before and after training," American Journal of Industrial Medicine, vol. 46, pp. 63-70, 2004.

[29] Y. Thamrin, D. Pisaniello, and S. Stewart, "Time trends and predictive factors for safety perceptions among incoming South Australian University students," Journal of Safety Research, 2011.

[30] M. Stromgren and R. Andersson, "The usage of safety management tools in Swedish municipalities," Safety Science, vol. 48, pp. 288-295, 2010.

[31] Zakaria Ismail and Omar Abdullah, "Employees' compliance with OSH rules and regulation: an exploratory study in manufacturing and construction firms," in Proc. the National Occupational Safety and Health Conference, The Gurney Resort Hotel and Residences Penang, Malaysia, April 21-22, 2003.

[32] T.-C. Wu, C.-W. Liu, and M.-C. Lu, "Safety climate in university and college laboratories: impact of organizational and individual factors," Journal of Safety Research, vol. 38, pp. 91-102, 2007.

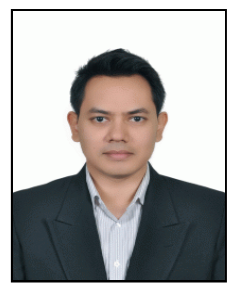

Shah Rollah Abdul Wahab is a senior lecturer at the Faculty of Management, Universiti Teknologi Malaysia, Johor Bahru Campus. He obtained his Ph.D. in Management from Universiti Teknologi Malaysia, Malaysia in 2011. He is with UTM for more than 11 years and currently active in research related to Safety Management, Transformational Leadership and Employee Training.

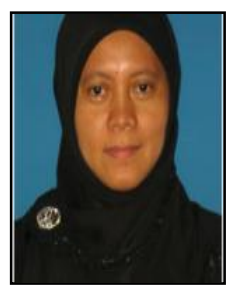

Azizah Rajab is a senior lecturer at the Language Academy, Universiti Teknologi Malaysia, Johor Bahru Campus. She obtained her Ph.D. in Applied Linguistics from Leicester University, United Kingdom in 1996. She is with UTM for more than 23 years and currently active in research related to Second Language, Educational Psychology, Higher Education and Social Science.

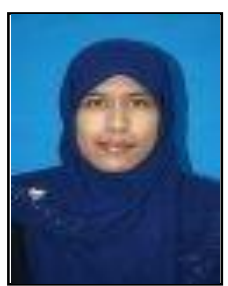

Roziana Shaari is a senior lecturer at the Faculty of Management, Universiti Teknologi Malaysia, Johor Bahru Campus. She obtained her Ph.D. in Computer Science from Universiti Teknologi Malaysia in 2009. She is with UTM for more than 15 years and currently active in research related to Human Resource Development, Knowledge Sharing, Individual and Organizational Learning.

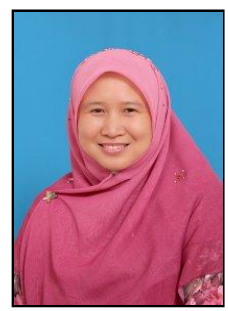

Siti Aisyah Abdul Rahman is a senior lecturer at the Faculty of Management, Universiti Teknolog Malaysia, Johor Bahru Campus. She obtained her $\mathrm{Ph} . \mathrm{D}$. in Psychology from Waikato University, New Zealand in 2010. She is with UTM for more than 13 years and currently active in research related to Industrial and Organizational Psychology.

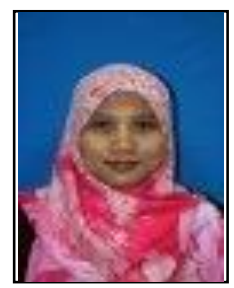

Maisarah Mohamed Saat was born in Johor, Malaysia on January 22, 1971. She obtained her bachelor in Accountancy from Universiti Utara Malaysia in year 1994 and Master in Accountancy from Universiti Kebangsaan Malaysia in 2001. She completed her Ph.D. in year 2010 from Curtin University, Western Australia.

She has previously worked as a finance officer at the Bursar Office of Universiti Teknologi Malaysia (UTM) before joining the academic world at Faculty of Management of UTM. She is now a senior lecturer at the Accounting and Finance Department and has been the Accounting Programme Coordinator since year 2011.

Dr. Saat is an associate member of Malaysia Institute of Accountants since 2003 and has been awarded the Excellence Service Award in 2006 and 2012. She publishes in local and international journals and other professional media; her main publication is on ethics, education and professional behaviour. 